\title{
Ramlibacter terrae sp. nov. and Ramlibacter montanisoli sp. nov., Isolated from Soil
}

\author{
Shehzad Abid Khan ${ }^{\dagger}$, Hyung Min Kim ${ }^{\dagger}$, Ju Hye Baek, Hye Su Jung, and Che Ok Jeon* \\ Department of Life Science, Chung-Ang University, Seoul 06974, Republic of Korea
}

\begin{abstract}
Two gram-negative, catalase-positive, strictly aerobic, and white colony-forming bacteria, strains $\mathrm{H}^{242}{ }^{\top}$ and $\mathrm{B} 156^{\top}$, were isolated from soil in South Korea. Cells of strain $\mathrm{H}^{242}{ }^{\top}$ were oxidase-positive and non-motile short rods, while those of strain $\mathrm{B}^{156^{\top}}$ were oxidase-negative and long non-motile rods. Ubiquinone- 8 was identified as the sole isoprenoid quinone in both strains. $C_{16: 0}$, cyclo- $C_{17: 0 r}$ and summed feature $3\left(C_{16: 1} \omega 7 c\right.$ and/or $\left.C_{16: 1} \omega 6 c\right)$ and phosphatidylethanolamine, phosphatidylglycerol, and diphosphatidylglycerol were identified in both strains as the major cellular fatty acids and polar lipids, respectively. The DNA G+C contents of strains $\mathrm{H}^{242}{ }^{\top}$ and $\mathrm{B} 156^{\top}$ were $69.4 \mathrm{~mol} \%$ and $69.3 \mathrm{~mol} \%$, respectively. Phylogenetic analyses based on 16S rRNA and 92 concatenated core gene sequences revealed that strains $\mathrm{H}_{242}{ }^{\top}$ and $\mathrm{B}_{156}{ }^{\top}$ formed distinct phylogenic lineages from other Ramlibacter type strains. The DNA-DNA hybridization (DDH) value between strains $\mathrm{H} 242^{\top}$ and $\mathrm{B} 156^{\top}$ was $24.6 \%$. Strains $\mathrm{H}^{242}{ }^{\top}$ and $\mathrm{B} 156^{\top}$ were most closely related to Ramlibacter ginsenosidimutans BXN5-27 ${ }^{\top}$ and Ramlibacter monticola G-3-2 ${ }^{\top}$ with $98.4 \%$ and $98.6 \%$ $16 S$ rRNA gene sequence similarities, respectively. Digital DDH values between strain $\mathrm{H}^{242}{ }^{\top}$ and $R$. ginsenosidimutans and between strain $B 156^{\top}$ and $R$. monticola were $23.5 \%$ and $26.1 \%$, respectively. Phenotypic, chemotaxonomic, and molecular analyses indicated that strains $\mathrm{H}_{242}{ }^{\top}$ and B $156^{\top}$ represent two novel species of the genus Ramlibacter, for which the names Ramlibacter terrae Sp. nov. and Ramlibacter montanisoli sp. nov., respectively, are proposed. The type strains of $R$. terrae and $R$. montanisoli are $\mathrm{H}_{242}{ }^{\top}$ (=KACC $21667^{\top}=\mathrm{JCM} 33922^{\top}$ ) and B156 ${ }^{\top}\left(=\mathrm{KACC}_{21665^{\top}}=\mathrm{JCM} 33920^{\top}\right)$, respectively.
\end{abstract}

Keywords: Ramlibacter terrae, Ramlibacter montanisoli, Betaproteobacteria, new taxa, soil

Received: May 18, 2021 Accepted: July 19, 2021

First published online: July 21, 2021

*Corresponding author Phone: +82-2-820-5864 E-mail: cojeon@cau.ac.kr

${ }^{\dagger}$ These authors contributed equally to this work.

Supplementary data for this paper are available on-line only at http://jmb.or.kr.

pISSN 1017-7825 elSSN 1738-8872

Copyright(C) 2021 by The Korean Society for Microbiology and Biotechnology

\section{Introduction}

The genus Ramlibacter, a new genus of the family Comamonadaceae in the class Betaproteobacteria, was first proposed by Heulin et al. with Ramlibacter tataouinensis as the type species, which was isolated from subdesert soil [1]. At the time of writing, the genus comprises 10 validly published species (https://lpsn.dsmz.de/genus/ ramlibacter) isolated primarily from soil habitats, such as subdesert soil [1], ginseng soil [2,3], forest soil [4-6], and garden soil $[7,8]$. An exception is Ramlibacter aquaticus $\mathrm{LMG} 30558^{\mathrm{T}}$, which was isolated from a water environment [9]. The genus Ramlibacter includes gram-negative, catalase-positive, oxidase-variable, aerobic, and non-motile (by flagella) rod or coccoid bacteria containing ubiquinone-8 (Q-8) and $\mathrm{C}_{16: 0}$, cyclo- $\mathrm{C}_{17: 0}$, and summed feature $3\left(\mathrm{C}_{16: 1} \omega 7 c\right.$ and/or $\left.\mathrm{C}_{16: 1} \omega 6 c\right)$ as the major respiratory quinone and fatty acids, respectively [1-9]. The DNA $\mathrm{G}+\mathrm{C}$ content of Ramlibacter species ranges from $62.0-70.6 \mathrm{~mol} \%$. In this study, we isolated two strains, presumably representing novel species of the genus Ramlibacter, from soil samples collected from different areas in South Korea and taxonomically characterized them using a polyphasic approach.

\section{Material and Methods}

Isolation and Cultivation

Strains $\mathrm{H} 242^{\mathrm{T}}$ and $\mathrm{B} 156^{\mathrm{T}}$ were isolated from flatland near a river $\left(37^{\circ} 15^{\prime} 04.2^{\prime \prime} \mathrm{N}, 128^{\circ} 32^{\prime} 26.3^{\prime \prime} \mathrm{E}\right)$ and mountain $\left(37^{\circ} 15^{\prime} 38.7^{\prime \prime} \mathrm{N}, 128^{\circ} 36^{\prime} 28.6^{\prime \prime} \mathrm{E}\right)$, respectively, in Gangwon Province of South Korea, according to a previously described procedure [10]. In brief, soil samples were collected in sterile plastic tubes and stored in an icebox for transport. The soil samples were resuspended and serially diluted in phosphate-buffered saline $(137 \mathrm{mM} \mathrm{NaCl}$, $\left.2.7 \mathrm{mM} \mathrm{KCl}, 10 \mathrm{mM} \mathrm{Na}_{2} \mathrm{HPO}_{4}, 2 \mathrm{mM} \mathrm{KH}_{2} \mathrm{PO}_{4}, \mathrm{pH} 7.2\right)$. The serially diluted aliquots (100 $\mu \mathrm{l}$ ) were spread on $2 \mathrm{~A}$ agar (BD, USA), and the agar plates were incubated aerobically at $30^{\circ} \mathrm{C}$ for $3 \mathrm{~d}$. The $16 \mathrm{~S}$ rRNA genes of colonies grown on R2A agar were PCR-amplified using the universal primers F1 (5'-AGA GTT TGA TCM TGG CTC AG$3^{\prime}$ ) and R13 (5'-TAC GGY TAC CTT GTT ACG ACT T-3') and double-digested with HaeIII and HhaI. The representative PCR amplicons of $16 \mathrm{~S}$ rRNA genes showing different fragment patterns were partially sequenced using the universal primer 340F (5'-CCT ACG GGA GGC AGC AG-3') at Macrogen (Korea). The resulting sequences were compared with all validly reported type strains using the Nucleotide Similarity Search program on 
the EzBioCloud server (http://www.ezbiocloud.net/identify) [11]. From the comparative analysis, strains $\mathrm{H} 242^{\mathrm{T}}$ and $\mathrm{B} 156^{\mathrm{T}}$ were selected as putative novel species of the genus Ramlibacter for further analyses. For full $16 \mathrm{~S}$ rRNA gene sequencing, the PCR amplicons of $16 \mathrm{~S}$ rRNA genes of strains $\mathrm{H} 242^{\mathrm{T}}$ and $\mathrm{B} 156^{\mathrm{T}}$ were further sequenced using universal primers 518R (5'-ATT ACC GCG GCT GCT GG-3') and 805F (5'-GAT TAG ATA CCC TGG TAG TC$3^{\prime}$ ), and the nucleotide sequences obtained using the $340 \mathrm{~F}, 518 \mathrm{R}$, and $805 \mathrm{~F}$ primers were assembled. Strains $\mathrm{H} 242^{\mathrm{T}}$ and $\mathrm{B} 156^{\mathrm{T}}$ were routinely cultured on R2A agar and/or in R2A broth for $2 \mathrm{~d}$ at $30^{\circ} \mathrm{C}$ and stored at $-80^{\circ} \mathrm{C}$ in $\mathrm{R} 2 \mathrm{~A}$ broth containing $15 \%(\mathrm{v} / \mathrm{v})$ glycerol for long-term preservation. $R$. tataouinensis KACC $11924^{\mathrm{T}}$, Ramlibacter ginsenosidimutans KACC $17527^{\mathrm{T}}$, Ramlibacter monticola KACC $19175^{\mathrm{T}}$, and Ramlibacter alkalitolerans KACC $19305^{\mathrm{T}}$ were obtained from the Korean Agricultural Culture Collection Center and used as reference strains for the comparison of phenotypic properties and fatty acid composition.

Phylogenetic Analysis Based on 16S rRNA Gene Sequences

The 16S rRNA gene sequence similarities of strains $\mathrm{H} 242^{\mathrm{T}}$ and $\mathrm{B} 156^{\mathrm{T}}$ with other bacterial type strains were calculated using the EzBioCloud server. The $16 \mathrm{~S}$ rRNA gene sequences of strains $\mathrm{H} 242^{\mathrm{T}}$ and $\mathrm{B} 156^{\mathrm{T}}$ and closely related type strains were aligned using the fast secondary-structure-aware infernal aligner available in the Ribosomal Database Project (RDP) [12]. Phylogenetic trees using the neighbor-joining (NJ), maximumlikelihood (ML), and maximum-parsimony (MP) algorithms with bootstrap values (1,000 replications) were constructed using MEGA7 software [13] based on the Kimura two-parameter model, the nearest-neighborinterchange heuristic search method, and the complete deletion options, respectively. Taxonomic classifications of strains $\mathrm{H} 242^{\mathrm{T}}$ and $\mathrm{B} 156^{\mathrm{T}}$ were confirmed using the RDP Naïve Bayesian rRNA Classifier (ver. 2.11; http:// rdp.cme.msu.edu/classifier/) [12] based on RDP 16S rRNA training set 16.

\section{Genome Sequencing and Phylogenomic Analysis}

For whole genome sequencing, the genomic DNA of strains $\mathrm{H}_{2} 42^{\mathrm{T}}$ and $\mathrm{B} 156^{\mathrm{T}}$ was extracted using the phenolchloroform extraction and ethanol precipitation method [14] and sequenced with an Oxford Nanopore MinION sequencer (Nanopore, UK). The resulting sequencing reads were de novo assembled using Unicycler (version 0.4.7) [15], and the quality of the assembled genomes was checked on the basis of their completeness and contamination rates using the CheckM program (version 1.0.4) [16]. Average nucleotide identity (ANI) and digital DNA-DNA hybridization (DDH) values among the genomes of strains $\mathrm{H}_{2} 42^{\mathrm{T}}$ and $\mathrm{B} 156^{\mathrm{T}}$ and closely related type strains were calculated using the stand-alone software available on the EzBioCloud server (www.ezbiocloud.net/sw/oat) [17] and the server-based Genome-to-Genome Distance Calculator version 2.1 http://ggdc.dsmz.de/distcalc2.php) [18], respectively. House-keeping core genes were extracted from the genome sequences of strains $\mathrm{H}_{2} 42^{\mathrm{T}}$ and $\mathrm{B} 156^{\mathrm{T}}$ and closely associated type strains using the up-to-date bacterial core gene (UBCG) pipeline (www.ezbiocloud.net/tools/ubcg) [19]. A phylogenomic ML tree with bootstrap values (1,000 replications) based on 92 concatenated housekeeping core genes was constructed using MEGA7 software.

\section{Phenotypic, Physiological, and Biochemical Analyses}

The growth of strains $\mathrm{H} 242^{\mathrm{T}}$ and $\mathrm{B} 156^{\mathrm{T}}$ was tested on R2A agar, tryptic soy agar (TSA; BD), nutrient agar (NA; $\mathrm{BD})$, marine agar (MA; BD), and laboratory-prepared Luria- Bertani agar for $3 \mathrm{~d}$ at $30^{\circ} \mathrm{C}$. The growth of strains $\mathrm{H} 242^{\mathrm{T}}$ and $\mathrm{B} 156^{\mathrm{T}}$ was evaluated at different temperatures $\left(4,10,15,20,25,30,37,40\right.$, and $\left.45^{\circ} \mathrm{C}\right)$ and $\mathrm{pH}$ values (5.0-11.0 at $0.5 \mathrm{pH}$ unit intervals) using R2A agar and R2A broth, respectively, for $3 \mathrm{~d}$. R2A broth with pH 5.0-5.5, $\mathrm{pH}$ 6.0-7.5, and $\mathrm{pH} 8.0-11.0$ was prepared using sodium citrate, $\mathrm{Na}_{2} \mathrm{HPO}_{4} / \mathrm{NaH}_{2} \mathrm{PO}_{4}$, and Tris- $\mathrm{HCl}$ buffers, respectively [20], and their $\mathrm{pH}$ values were adjusted if necessary after autoclaving (at $121^{\circ} \mathrm{C}$ for $15 \mathrm{~min}$ ). The growth of strains $\mathrm{H} 242^{\mathrm{T}}$ and $\mathrm{B} 156^{\mathrm{T}}$ was examined in $\mathrm{R} 2 \mathrm{~A}$ broth with different $\mathrm{NaCl}$ concentrations $(0 \%-4 \%$ at $0.5 \%$ intervals, $\mathrm{w} / \mathrm{v}$ ). The biochemical and physiological properties of strains $\mathrm{H} 242^{\mathrm{T}}$ and $\mathrm{B} 156^{\mathrm{T}}$ were tested using cells grown on $\mathrm{R} 2 \mathrm{~A}$ agar after aerobic incubation for $2 \mathrm{~d}$ at $30^{\circ} \mathrm{C}$. Gram staining was performed using a Gram stain kit (bioMérieux, France), according to the manufacturer's instructions. The gliding motility of strains $\mathrm{H} 242^{\mathrm{T}}$ and $\mathrm{B} 156^{\mathrm{T}}$ was tested using R2A containing $0.3 \%$ agar as described previously [21]. The cell morphology of strains $\mathrm{H} 242^{\mathrm{T}}$ and $\mathrm{B} 156^{\mathrm{T}}$ was inspected using phase-contrast microscopy (Carl Zeiss, Germany) and transmission electron microscopy (JEM-1010; Jeol, Japan). Oxidase and catalase activities were tested by oxidation of $1 \%(\mathrm{w} / \mathrm{v}$ ) tetramethyl- $p$-phenylenediamine (Merck, USA) and by the production of oxygen bubbles in $3 \%(\mathrm{v} / \mathrm{v})$ aqueous hydrogen peroxide solution, respectively [22]. To assess the anaerobic growth of strains $\mathrm{H} 242^{\mathrm{T}}$ and $\mathrm{B} 156^{\mathrm{T}}$, both strains were streaked on $\mathrm{R} 2 \mathrm{~A}$ agar and incubated at $30^{\circ} \mathrm{C}$ for 21 days under anaerobic conditions prepared using the GasPak Plus system (BBL, USA). The properties of strains $\mathrm{H}_{2} 42^{\mathrm{T}}$ and $\mathrm{B} 156^{\mathrm{T}}$ and their four closely related reference strains were investigated in parallel under the same growth conditions. Hydrolysis of tyrosine, casein, esculin, gelatin, starch, Tween 20, and Tween 80 was tested on R2A agar following the methods described by Lányi and Tindall et al. [22, 23]. Additional biochemical features and enzymatic activities were tested using the API 20NE and API ZYM systems (bioMérieux), respectively, according to the manufacturer's instructions.

\section{Chemotaxonomic Analyses}

For the analysis of respiratory quinones, strains $\mathrm{H} 242^{\mathrm{T}}$ and $\mathrm{B} 156^{\mathrm{T}}$ were aerobically cultivated to their exponential growth phases in R2A broth at $30^{\circ} \mathrm{C}$. Microbial cells were harvested and their isoprenoid quinones were extracted, according to the method of Minnikin et al. [24], and analyzed using a model LC-20A HPLC system (Shimadzu, Japan) equipped with a diode array detector (SPD-M20A; Shimadzu) and a reversed-phase column $\left(250 \times 4.6 \mathrm{~mm}\right.$, Kromasil; Akzo Nobel, Japan). For cellular fatty acid analysis, strains $\mathrm{H} 242^{\mathrm{T}}$ and B156 ${ }^{\mathrm{T}}$ and four reference strains were cultivated in R2A broth at their optimal temperatures and their microbial cells were 
harvested at the same growth stage (exponential phase, optical density, $\mathrm{OD}_{600}=0.8$ ). Cellular fatty acids of microbial cells were saponified, methylated, and extracted using the standard MIDI protocol. Fatty acid methyl esters were analyzed by gas chromatography (Hewlett Packard 6890, USA) and identified using the RTSBA6 database of the Microbial Identification System (Sherlock ver. 6.0B) [25]. Polar lipids of strains $\mathrm{H} 242^{\mathrm{T}}$ and B156 were extracted from cells harvested during the exponential growth phase and analyzed by two-dimensional thinlayer chromatography (TLC), according to the procedure described by Minnikin et al. [26]. The following reagents were used to identify different polar lipids: $10 \%$ ethanolic molybdophosphoric acid (for total polar lipids), ninhydrin (for aminolipids), Dittmer-Lester reagent (for phospholipids), and $\alpha$-naphthol/sulfuric acid (for glycolipids). Major polar lipids (diphosphatidylglycerol, phosphatidylglycerol, and phosphatidylethanolamine) identified from strains $\mathrm{H} 242^{\mathrm{T}}$ and $\mathrm{B} 156^{\mathrm{T}}$ were confirmed using standard polar lipid compounds purchased from Sigma-Aldrich (USA).

\section{Results and Discussion}

Molecular Phylogenetic Analysis

Almost complete $16 \mathrm{~S}$ rRNA gene sequences of strains $\mathrm{H}_{242} 2^{\mathrm{T}}$ (1,460 nucleotides) and $\mathrm{B} 156^{\mathrm{T}}$ (1,453 nucleotides) were obtained through sequencing and assembly of their $16 \mathrm{~S}$ rRNA gene amplicons using the $340 \mathrm{~F}, 518 \mathrm{R}$, and $805 \mathrm{~F}$ primers. Comparative analysis using the EzTaxon program based on the $16 \mathrm{~S}$ rRNA gene sequences revealed that strain $\mathrm{H} 242^{\mathrm{T}}$ was most closely related to R. ginsenosidimutans $\mathrm{BXN} 5-27^{\mathrm{T}}$ and R. monticola $\mathrm{G}-3-2^{\mathrm{T}}$ with $98.4 \%$ and $97.7 \% 16 \mathrm{~S}$ rRNA gene sequence similarities, respectively, whereas strain $\mathrm{B} 156^{\mathrm{T}}$ was most closely related to R. monticola G-3-2 $2^{\mathrm{T}}$ and R. alkalitolerans $\mathrm{CJ} 661^{\mathrm{T}}$ with $98.7 \%$ and $98.3 \% 16 \mathrm{~S}$ rRNA gene sequence similarities, respectively. Phylogenetic analysis based on $16 \mathrm{~S}$ rRNA gene sequences using the NJ algorithm revealed that strains $\mathrm{H} 242^{\mathrm{T}}$ and $\mathrm{B} 156^{\mathrm{T}}$ formed distinct phylogenic lineages from other Ramlibacter type strains (Fig. 1), as did the ML and MP algorithms (Fig. S1). Taxonomic analysis of strains $\mathrm{H}_{2} 42^{\mathrm{T}}$ and $\mathrm{B} 156^{\mathrm{T}}$ using the RDP classifier tool

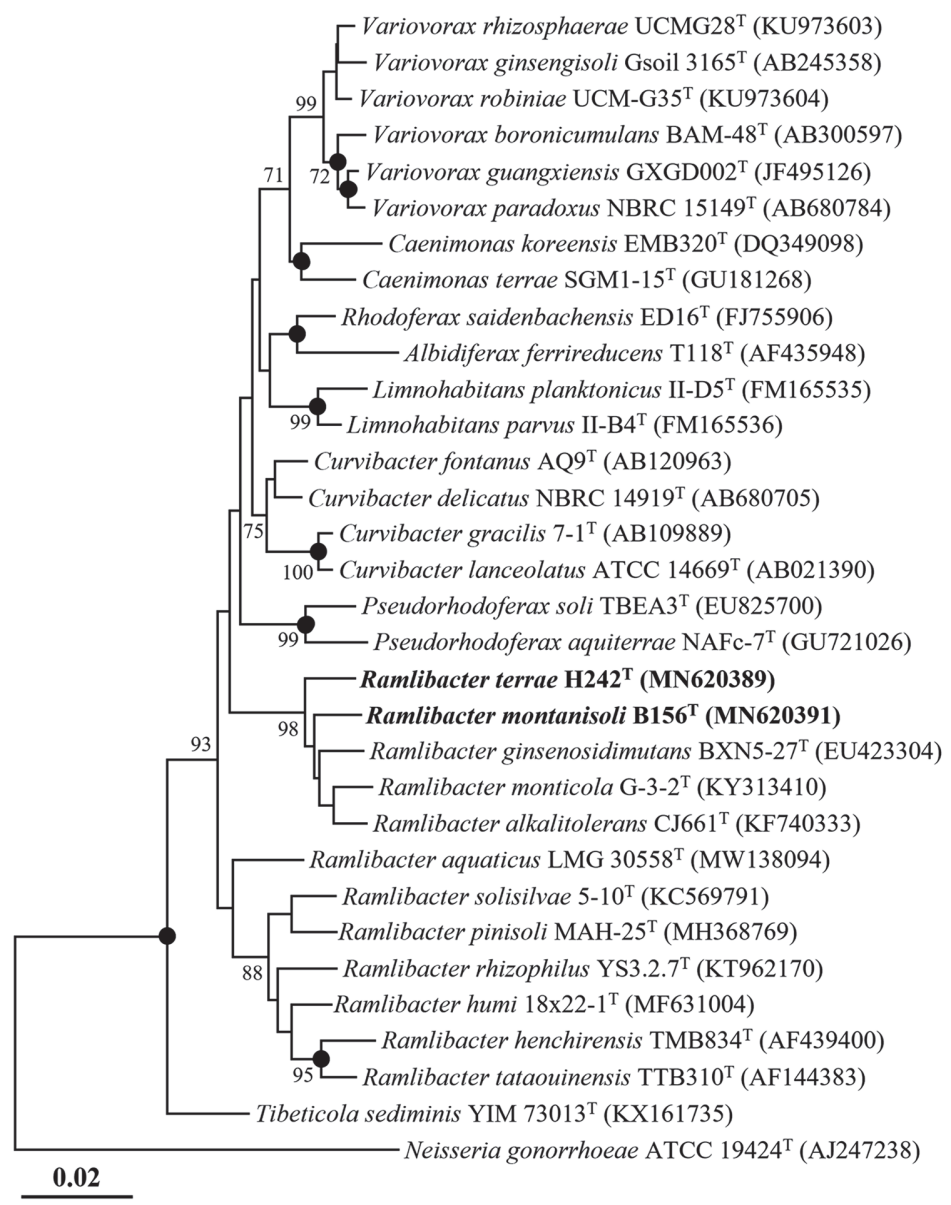

Fig. 1. A neighbor-joining tree (NJ) showing the phylogenetic relationships between strains $\mathrm{H} 242^{\mathrm{T}}$ and $\mathrm{B}^{156^{\mathrm{T}}}$ and closely related species, based on $16 \mathrm{~S}$ rRNA gene sequences. Bootstrap values (based on 1,000 replication) greater than $70 \%$ are shown at branch points. The filled circles $(-)$ indicate branches that were commonly recovered using the NJ, maximum likelihood, and maximum parsimony algorithms. Neisseria gonorrhoeae ATCC $19424^{\mathrm{T}}$ (AJ247238) was used as an outgroup. Scale bar, 0.02 substitutions per nucleotide position. 
also suggested that strains $\mathrm{H} 242^{\mathrm{T}}$ and $\mathrm{B} 156^{\mathrm{T}}$ could be classified as unclassified species of the genus Ramlibacter. Sequence similarity and phylogenetic analyses based on $16 \mathrm{~S}$ rRNA gene sequences suggested that strains $\mathrm{H} 242^{\mathrm{T}}$ and $\mathrm{B} 156^{\mathrm{T}}$ could represent novel species of the genus Ramlibacter.

\section{Genomic and Phylogenomic Analyses}

The de novo assembly of the genome sequencing data of strain $\mathrm{H} 242^{\mathrm{T}}$ resulted in a complete genome with an average genome coverage of $306.0 \times$, whereas that of strain $B 156^{T}$ produced two contigs that were $4,459,501 \mathrm{bp}$ and $293,893 \mathrm{bp}$ in size, with an average genome coverage of $246.0 \times$. The completeness values of strains $\mathrm{H} 242^{1}$ and B156 ${ }^{\mathrm{T}}$ were $95.6 \%$ and $93.4 \%$, respectively, and the contamination rates of these strains were $0 \%$ and $1.6 \%$, respectively, and all values met the criteria for high-quality genomes (completeness $\geq 90 \%$ and contamination $\leq$ $10 \%$ ) [16]. The complete genome of strain $\mathrm{H} 242^{\mathrm{T}}$ was 5,277,406 bp in size, and 5,653 total genes, 2,807 proteincoding genes, and 45 tRNA genes encoding 20 amino acids were predicted from the genome. The draft genome of strain $\mathrm{B} 156^{\mathrm{T}}$ was $4,753,394 \mathrm{bp}$ in size, and 4,741 total genes, 3,639 protein-coding genes, and 44 tRNA genes encoding 20 amino acids were predicted from the genome. The 16S rRNA gene sequences of strains $\mathrm{H} 242^{\mathrm{T}}$ and $B 156^{\mathrm{T}}$ obtained using the PCR approach were identical to those in their genomes. The G+C contents of strains $\mathrm{H} 242^{\mathrm{T}}$ and $\mathrm{B} 156^{\mathrm{T}}$ calculated from their genomes were $69.4 \mathrm{~mol} \%$ and $69.3 \mathrm{~mol} \%$, respectively, which were in the ranges of $\mathrm{G}+\mathrm{C}$ contents of Ramlibacter species. The ANI and digital DDH values between strains $\mathrm{H} 242^{\mathrm{T}}$ and $\mathrm{B} 156^{\mathrm{T}}$ were $81.9 \%$ and $24.6 \%$, respectively, suggesting that strains $\mathrm{H} 242^{\mathrm{T}}$ and $\mathrm{B} 156^{\mathrm{T}}$ are different species of the genus Ramlibacter. The ANI and digital DDH values between strain $\mathrm{H} 242^{\mathrm{T}}$ and $R$. ginsenosidimutans KACC $17527^{\mathrm{T}}$, the most closely related type strain to strain $\mathrm{H} 242^{\mathrm{T}}$, were $80.2 \%$ and $23.5 \%$, respectively. Those between strain $\mathrm{B} 156^{\mathrm{T}}$ and R. monticola KACC $19175^{\mathrm{T}}$, the most closely related type strain to strain $\mathrm{B} 156^{\mathrm{T}}$, were $83.1 \%$ and $26.1 \%$, respectively. These values were clearly lower than the thresholds (ANI, $95 \%$; digital DDH, 70\%) for prokaryotic species delineation [27]. Additionally, the phylogenomic tree based on 92 orthologous housekeeping core genes revealed that strains $\mathrm{H} 242^{\mathrm{T}}$ and $\mathrm{B} 156^{\mathrm{T}}$ formed distinct phylogenetic lineages within the genus Ramlibacter (Fig. 2). In conclusion, the genome relatedness and phylogenomic analyses of strains $\mathrm{H} 242^{\mathrm{T}}$ and $\mathrm{B} 156^{\mathrm{T}}$ with closely related type strains clearly suggested that they could represent two novel species of the genus Ramlibacter.

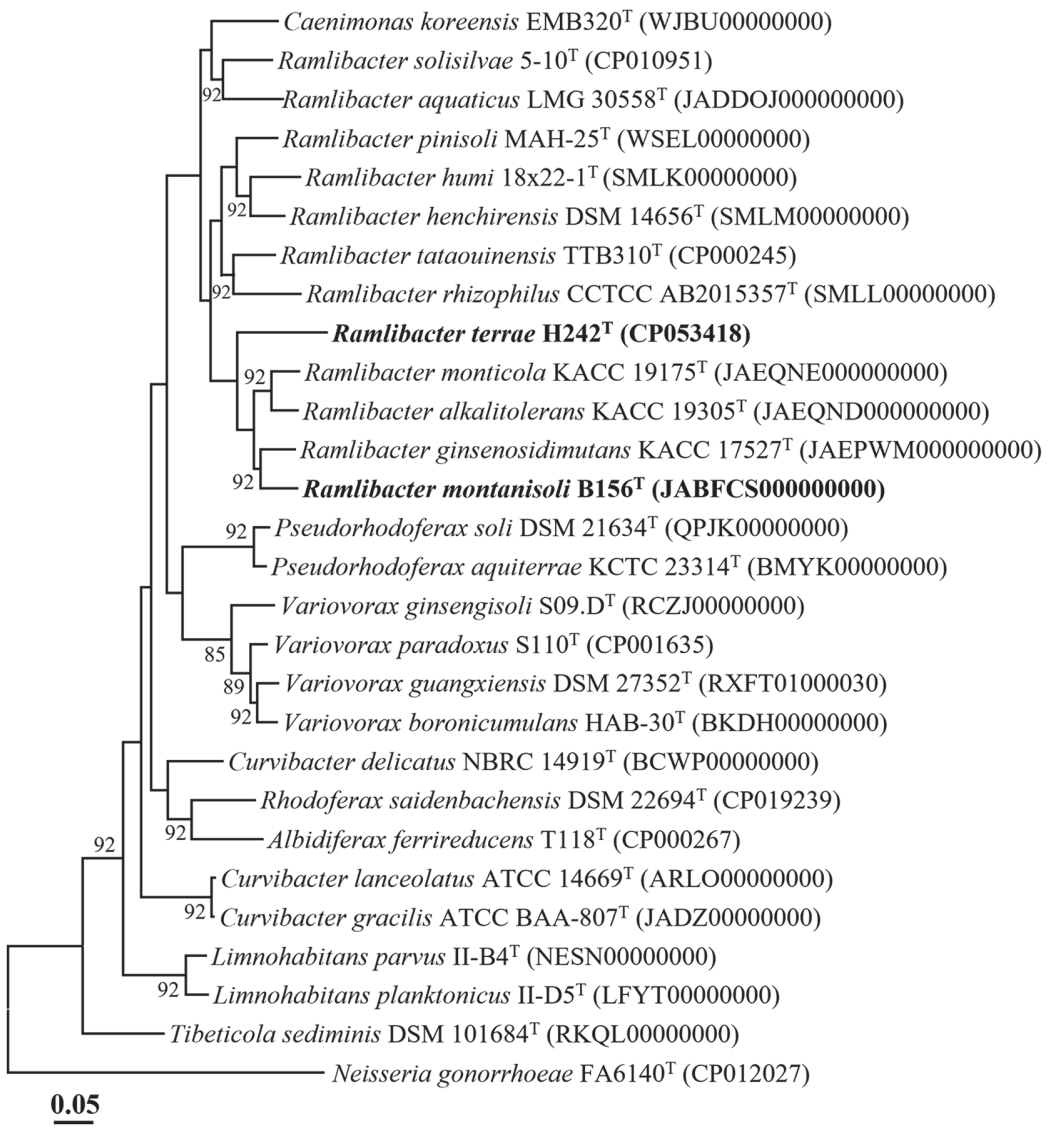

Fig. 2. A phylogenomic tree showing the phylogenetic relationships between strains $\mathrm{H}^{242}{ }^{\mathrm{T}}$ and $\mathrm{B} 156^{\mathrm{T}}$ and closely related species, based on the $\mathbf{9 2}$ concatenated housekeeping core gene sequences. Bootstrap values (based on 1,000 replication) greater than $70 \%$ are shown at branch points. Neisseria gonorrhoeae FA6140 ${ }^{\mathrm{T}}$ (CP012027) was used as an outgroup. Bar, 0.05 substitutions per nucleotide position. 
Table 1. Differential phenotype characteristics of strains $\mathrm{H}_{242}{ }^{\mathrm{T}}$ and $\mathrm{B} 156^{\mathrm{T}}$ and closely related type strains of the genus Ramlibacter.

\begin{tabular}{|c|c|c|c|c|c|c|}
\hline Characteristic & $1^{*}$ & $2^{*}$ & 3 & 4 & 5 & 6 \\
\hline Isolation source & Forest soil & Forest soil & Forest soil & Ginseng field & Ginseng field & Desert soil \\
\hline Colony color & White & White & Brown & White & White & Yellow-orange \\
\hline Cell morphology & Short rods & Long rods & Short rods & Long rods & Short rods & Short rods \\
\hline Oxidase & + & - & - & + & + & + \\
\hline Gliding motility & - & - & - & + & - & + \\
\hline \multicolumn{7}{|l|}{ Optimum growth at: } \\
\hline Temperature $\left({ }^{\circ} \mathrm{C}\right)$ & 30 & 30 & $20-32$ & $25-37$ & 30 & 30 \\
\hline $\mathrm{pH}$ & $7.0-7.5$ & $7.0-7.5$ & $6.5-8.0$ & 7.0 & 7.0 & 7.5 \\
\hline \multicolumn{7}{|l|}{ Hydrolysis* of: } \\
\hline Casein, starch & - & - & - & + & - & + \\
\hline Tween 80 , Tween 20 , tyrosine & - & - & - & + & - & - \\
\hline \multicolumn{7}{|l|}{ Enzyme activity (API ZYM)* of: } \\
\hline $\begin{array}{l}\text { Alkaline phosphatase, lipase } \\
\text { (C14) }\end{array}$ & + & + & - & + & + & - \\
\hline Esterase (C4) & + & + & - & + & + & + \\
\hline $\begin{array}{l}\text { Valine arylamidase, acid } \\
\text { phosphatase }\end{array}$ & + & + & + & + & + & - \\
\hline Cystine arylamidase & + & + & - & - & - & - \\
\hline $\begin{array}{l}\beta \text {-Glucosidase, } N \text {-acetyl- } \beta \text { - } \\
\text { glucosaminidase }\end{array}$ & - & - & - & + & - & - \\
\hline Gelatinase & + & - & + & - & + & - \\
\hline Urease & - & - & + & - & - & - \\
\hline \multicolumn{7}{|l|}{ Assimilation (API 20NE)* of: } \\
\hline L-Arabinose & + & - & + & + & - & - \\
\hline$N$-Acetyl-glucosamine & + & - & + & - & - & + \\
\hline D-Maltose & - & + & + & - & + & + \\
\hline Potassium gluconate & - & - & + & - & - & + \\
\hline Trisodium citrate & + & - & + & - & + & - \\
\hline DNA G+C content $(\mathrm{mol} \%)^{\dagger}$ & 69.4 & 69.3 & 69.3 & 68.7 & 69.2 & 70.0 \\
\hline
\end{tabular}

Taxa: 1, strain $\mathrm{H} 242^{\mathrm{T}}$ (this study); 2, strain $\mathrm{B} 156^{\mathrm{T}}$ (this study); 3, R. monticola KACC $19175^{\mathrm{T}}$ [5]; 4, R. ginsenosidimutans $\mathrm{KACC}$ $17527^{\mathrm{T}}[3] ; 5$, R. alkalitolerans KACC $19305^{\mathrm{T}}$ [2]; 6, R. tataouinensis KACC $11924^{\mathrm{T}}$ [1]. All strains are aerobic and positive for the following characteristics: catalase activity, nitrate reduction ${ }^{\star}$, esculin hydrolysis ${ }^{\star}$, activity ${ }^{*}$ of esterase lipase (C8), leucine arylamidase, and naphthol-AS-BI-phosphohydrolase, and assimilation* of D-glucose, D-mannose, D-mannitol, and malic acid. All strains are negative for the following characteristics: flagellar motility, indole production, glucose fermentation, activity ${ }^{\star}$ of arginine dihydrolase, trypsin, $\alpha$-chymotrypsin, $\alpha$-galactosidase, $\beta$-galactosidase, $\beta$-glucuronidase, $\alpha$-glucosidase, $\alpha$-mannosidase, and $\alpha$-fucosidase, and assimilation ${ }^{\star}$ of capric acid, adipic acid, and phenyl acetate. Symbols: + , positive; - , negative.

*These analyses were conducted under the same conditions used in this study.

${ }^{\dagger}$ The DNA G+C contents were calculated from the whole genome sequences in this study.

\section{Phenotypic, Physiological, and Biochemical Characteristics}

Both strains $\mathrm{H} 242^{\mathrm{T}}$ and $\mathrm{B} 156^{\mathrm{T}}$ grew well on $\mathrm{R} 2 \mathrm{~A}$ agar and exhibited relatively good growth on NA and TSA, but did not grow on MA. Strain $\mathrm{H} 242^{\mathrm{T}}$ grew slowly on LB agar, whereas strain B156 ${ }^{\mathrm{T}}$ did not grow on it. Both strains formed white colonies on R2A agar. Cells of strains $\mathrm{H} 242^{\mathrm{T}}$ were gram-negative and non-motile short rods, 0.6-0.7 $\mu \mathrm{m}$ in width, and 1-1.2 $\mu \mathrm{m}$ in length, whereas those of strain B156 ${ }^{\mathrm{T}}$ were gram-negative and non-motile long and slender rods, $0.3-0.4 \mu \mathrm{m}$ in width, and 1.8-2.2 $\mu \mathrm{m}$ in length (Fig. S2). Neither strain showed any growth under anaerobic conditions, suggesting that they are strictly aerobic. Many phenotypic properties, such as reduction of nitrate, activity of catalase, esterase lipase (C8), leucine arylamidase, and naphthol-AS-BI-phosphohydrolase, and assimilation of D-glucose, D-mannose, D-mannitol, and malic acid, were common between strains $\mathrm{H} 242^{\mathrm{T}}$ and $\mathrm{B} 156^{\mathrm{T}}$ and their closely related Ramlibacter species, but many other phenotypic properties, described in Table 1 , differentiated strains $\mathrm{H} 242^{\mathrm{T}}$ and $\mathrm{B} 156^{\mathrm{T}}$ from their closely related Ramlibacter species.

\section{Chemotaxonomic Characteristics}

Q-8 was detected as the sole respiratory quinone from strains $\mathrm{H} 242^{\mathrm{T}}$ and $\mathrm{B} 156^{\mathrm{T}}$, which is in agreement with other species of the genus Ramlibacter [1-9]. Of the major cellular fatty acids ( $>10 \%$ of the total fatty acids), strain $\mathrm{H} 242^{\mathrm{T}}$ contained $\mathrm{C}_{16: 0}(26.9 \%)$, cyclo- $\mathrm{C}_{17: 0}(16.5 \%)$, summed feature $3\left(\mathrm{C}_{16: 1} \omega 7 c\right.$ and/or $\left.\mathrm{C}_{16: 1} \omega 6 c, 20.3 \%\right)$ and

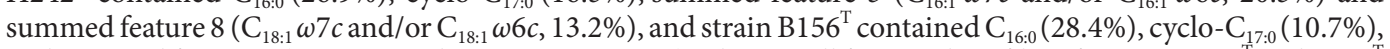
and summed feature $3\left(\mathrm{C}_{16: 1} \omega 7 c\right.$ and/or $\left.\mathrm{C}_{16: 1} \omega 6 c, 22.4 \%\right)$. The overall fatty acid profiles of strains $\mathrm{H} 242^{\mathrm{T}}$ and $\mathrm{B} 156^{\mathrm{T}}$ were generally similar to those of closely related Ramlibacter reference strains, but there were some differences in both components and compositions (Table 2). For example, $\mathrm{C}_{10: 0}$ was not detected in strain $\mathrm{H}_{2} 42^{\mathrm{T}}$ but was detected in other strains, and iso- $\mathrm{C}_{16: 0}$ was not detected in strain $\mathrm{B} 156^{\mathrm{T}}$ but was detected in $R$. monticola, the most closely related species. $\mathrm{C}_{10: 0} 3-\mathrm{OH}$ was detected in strains $\mathrm{H} 242^{\mathrm{T}}$ and $\mathrm{B} 156^{\mathrm{T}}$ as the sole hydroxy fatty acid. Phosphatidylglycerol, diphosphatidylglycerol, and phosphatidylethanolamine were identified from strains $\mathrm{H}_{242} 2^{\mathrm{T}}$ and $\mathrm{B} 156^{\mathrm{T}}$ as the 
Table 2. Cellular fatty acid compositions (\%) of strains $\mathrm{H}_{242}{ }^{\mathrm{T}}$ and $\mathrm{B} 156^{\mathrm{T}}$ and closely related type strains of the genus Ramlibacter.

\begin{tabular}{|c|c|c|c|c|c|c|}
\hline Fatty acid & 1 & 2 & 3 & 4 & 5 & 6 \\
\hline \multicolumn{7}{|l|}{ Saturated: } \\
\hline $\mathrm{C}_{10: 0}$ & - & 3.2 & $\operatorname{tr}$ & $\operatorname{tr}$ & $\operatorname{tr}$ & 2.1 \\
\hline $\mathrm{C}_{12: 0}$ & 3.1 & 1.7 & 4.0 & 2.3 & 4.4 & 8.8 \\
\hline $\mathrm{C}_{14: 0}$ & 4.2 & 2.2 & 5.6 & 6.0 & 5.4 & 3.8 \\
\hline $\mathrm{C}_{16: 0}$ & 26.9 & 28.4 & 28.7 & 41.4 & 31.5 & 16.6 \\
\hline $\mathrm{C}_{17: 0}$ & 4.2 & 1.3 & 1.6 & - & $\operatorname{tr}$ & 2.2 \\
\hline $\mathrm{C}_{18: 0}$ & 1.7 & 1.3 & $\operatorname{tr}$ & 1.0 & $\operatorname{tr}$ & 1.1 \\
\hline $\mathrm{C}_{19: 0}$ & $\operatorname{tr}$ & - & 1.4 & 2.2 & 1.2 & - \\
\hline \multicolumn{7}{|l|}{ Unsaturated: } \\
\hline $\mathrm{C}_{14: 1} \omega 5 c$ & $\operatorname{tr}$ & 1.1 & $\operatorname{tr}$ & $\operatorname{tr}$ & $\operatorname{tr}$ & 7.1 \\
\hline $\mathrm{C}_{15: 1} \omega 5 c$ & - & 3.9 & 2.7 & - & - & 6.3 \\
\hline $\mathrm{C}_{15: 1} \omega 6 c$ & $\operatorname{tr}$ & 1.1 & 1.1 & $\operatorname{tr}$ & 2.1 & 2.1 \\
\hline Cyclo- $\mathrm{C}_{17: 0}$ & 16.5 & 10.7 & 12.2 & 19.5 & 14.9 & 11.2 \\
\hline \multicolumn{7}{|l|}{ Branched: } \\
\hline iso- $\mathrm{C}_{16: 0}$ & - & - & 2.3 & - & $\operatorname{tr}$ & - \\
\hline iso- $\mathrm{C}_{17: 0}$ & 1.4 & 1.1 & $\operatorname{tr}$ & $\operatorname{tr}$ & $\operatorname{tr}$ & $\operatorname{tr}$ \\
\hline \multicolumn{7}{|l|}{ Hydroxy: } \\
\hline $\mathrm{C}_{10: 0} 3-\mathrm{OH}$ & 4.5 & 9.4 & 6.9 & 7.1 & 5.1 & 4.3 \\
\hline $\mathrm{C}_{12: 0} 2-\mathrm{OH}$ & - & - & - & 1.9 & 2.3 & - \\
\hline \multicolumn{7}{|c|}{ Summed feature ${ }^{\star}$ : } \\
\hline 3 & 20.3 & 22.4 & 18.3 & 11.9 & 19.8 & 21.4 \\
\hline 5 & 1.1 & 1.2 & 2.4 & 3.5 & 1.9 & 1.4 \\
\hline 8 & 13.2 & 8.9 & 9.3 & $\operatorname{tr}$ & 8.6 & 8.3 \\
\hline
\end{tabular}

Taxa: 1, strain $\mathrm{H} 242^{\mathrm{T}} ; 2$, strain $\mathrm{B} 156^{\mathrm{T}} ; 3$, R. monticola KACC $19175^{\mathrm{T}} ; 4$, R. ginsenosidimutans KACC $17527^{\mathrm{T}} ; 5$, R. alkalitolerans KACC $19305^{\mathrm{T}} ; 6$, R. tataouinensis KACC $11924^{\mathrm{T}}$. Fatty acids amounting to less than $1.0 \%$ in all strains are not shown. Major fatty acids $(>10.0 \%)$ are highlighted in bold; tr, trace amount $(<1.0 \%) ;-$, not detected. All data were obtained in this study.

${ }^{*}$ Summed features are fatty acids that cannot be resolved reliably from another fatty acid using the chromatographic conditions chosen. The MIDI system groups these fatty acids together as one feature with a single percentage of the total. Summed features 3,5 , and 8 contain $\mathrm{C}_{16: 1} \omega 7 c$ and/or $\mathrm{C}_{16: 1} \omega 6 c, \mathrm{C}_{18: 0}$ ante and/or $\mathrm{C}_{18: 2} \omega 6,9 c$, and $\mathrm{C}_{18: 1} \omega 7 c$ and/or $\mathrm{C}_{18: 1} \omega 6 c$, respectively.

major polar lipids, and an unidentified aminophospholipid was additionally identified from strain $\mathrm{B} 156^{\mathrm{T}}$ as a minor polar lipid (Fig. S3). The polar lipid profiles of both strains were in accordance with those of other Ramlibacter species $[2,5]$. In conclusion, the phylogenetic analysis, genome relatedness, and phenotypic and chemotaxonomic features suggest that strains $\mathrm{H} 242^{\mathrm{T}}$ and $\mathrm{B} 156^{\mathrm{T}}$ represent two novel species of the genus Ramlibacter, for which the names Ramlibacter terrae sp. nov. and Ramlibacter montanisoli sp. nov. are proposed.

\section{Description of Ramlibacter terrae sp. nov.}

Ramlibacter terrae (ter'rae. L. gen. n. terrae of the soil).

Cells are gram-negative, strictly aerobic, and short rods without flagellum $(0.6-0.7 \mu \mathrm{m}$ in width and $1-1.2 \mu \mathrm{m}$ in length). Gliding motility is negative. Colonies on R2A agar are white-colored, circular, smooth, and convex being $1-2 \mathrm{~mm}$ in diameter after $3 \mathrm{~d}$ of incubation at $30^{\circ} \mathrm{C}$. Growth occurs at $10-30^{\circ} \mathrm{C}$ (optimum, $30^{\circ} \mathrm{C}$ ), pH $6.0-9.0$ (optimum, 7.0-7.5), and in the presence of $0-4.5 \% \mathrm{NaCl}$ (optimum, in $\mathrm{R} 2 \mathrm{~A}$ broth without the addition of $\mathrm{NaCl}$ ). Catalase- and oxidase-positive. Nitrate is reduced to nitrite and nitrogen gas is produced. Indole production and glucose fermentation are negative. Hydrolyzes gelatin and esculin, but not Tween 80, urea, casein, Tween 20 , tyrosine, and starch. Positive for alkaline phosphatase, esterase (C4), lipase (C14), esterase lipase (C8), valine arylamidase, acid phosphatase, leucine arylamidase, cystine arylamidase, and naphthol-AS-BI-phosphohydrolase activity, but negative for arginine dihydrolase, trypsin, $\alpha$-chymotrypsin, $\alpha$-galactosidase, $\beta$-galactosidase, $\beta$ glucuronidase, $\alpha$-glucosidase, $\beta$-glucosidase, $N$-acetyl- $\beta$-glucosaminidase, $\alpha$-mannosidase, and $\alpha$-fucosidase activity. Assimilation of D-glucose, D-mannose, D-mannitol, malic acid, L-arabinose, $\mathrm{N}$-acetyl-glucosamine, and trisodium citrate is positive, but assimilation of D-maltose, potassium gluconate, capric acid, adipic acid, and phenyl acetate is negative. Q-8 is the sole isoprenoid quinone. The major cellular fatty acids $(>10 \%)$ are $\mathrm{C}_{16: 0}$, cyclo- $\mathrm{C}_{17: 0}$, summed feature $3\left(\mathrm{C}_{16: 1} \omega 7 c\right.$ and/or $\left.\mathrm{C}_{16: 1} \omega 6 c\right)$, and summed feature $8\left(\mathrm{C}_{18: 1} \omega 7 c\right.$ and/or $\left.\mathrm{C}_{18: 1} \omega 6 c\right)$. Phosphatidylglycerol, diphosphatidylglycerol, and phosphatidylethanolamine are the major polar lipids.

The type strain is $\mathrm{H} 242^{\mathrm{T}}\left(=\mathrm{KACC} 21667^{\mathrm{T}}=\mathrm{JCM} 33922^{\mathrm{T}}\right)$, isolated from flatland soil of Gangwon Province in South Korea. The DNA G+C content calculated from the whole genome sequence of the type strain is $69.4 \mathrm{~mol} \%$. The GenBank accession numbers of the 16S rRNA gene and genome sequences of strain $\mathrm{H}_{2} 42^{\mathrm{T}}$ are MN620389 and CP053418, respectively.

\section{Description of Ramlibacter montanisoli sp. nov.}

Ramlibacter montanisoli (mon.ta.ni.so'li. L. masc. adj. montanus of a mountain; L. neut. n. solum soil; N.L. gen. n. montanisoli of mountain soil).

Cells are gram-negative, strictly aerobic, and long and slender rods without flagella $(0.3-0.4 \mu \mathrm{m}$ in width and 
1.8-2.2 $\mu \mathrm{m}$ in length). Gliding motility is negative. Colonies on R2A agar are white-colored, circular, smooth, and convex being $1-1.5 \mathrm{~mm}$ in diameter after $3 \mathrm{~d}$ of incubation at $30^{\circ} \mathrm{C}$. Catalase-positive and oxidase-negative. Growth occurs at $20-40^{\circ} \mathrm{C}$ (optimum, $30^{\circ} \mathrm{C}$ ) and $\mathrm{pH}$ 6.0-9.0 (optimum, 7.0-7.5) and in R2A broth (does not grow in $\mathrm{R} 2 \mathrm{~A}$ broth with the addition of $0.5 \% \mathrm{NaCl}$ ). Nitrate is reduced to nitrite and nitrogen gas is produced. Indole production and glucose fermentation are negative. Hydrolyzes esculin and gelatin, but not casein, urea, Tween 80 , Tween 20, tyrosine, and starch. Positive for alkaline phosphatase, esterase (C4), lipase (C14), esterase lipase (C8), leucine arylamidase, valine arylamidase, cystine arylamidase, acid phosphatase, and naphthol-AS-BIphosphohydrolase activity, but negative for trypsin, $\alpha$-chymotrypsin, $\alpha$-galactosidase, $\beta$-galactosidase, $\alpha$ glucosidase, $\beta$-glucosidase, $\beta$-glucuronidase, $N$-acetyl- $\beta$-glucosaminidase, $\alpha$-mannosidase, and $\alpha$-fucosidase activity. Assimilation of D-glucose, D-mannose, D-mannitol, malic acid, and D-maltose is positive, but assimilation of L-arabinose, capric acid, potassium gluconate, $\mathrm{N}$-acetyl-glucosamine, adipic acid, trisodium citrate, and phenyl acetate is negative. Q-8 is the sole isoprenoid quinone. The major cellular fatty acids $(>10 \%)$ are $\mathrm{C}_{16: 0}$, cyclo- $\mathrm{C}_{17: 0}$, and summed feature $3\left(\mathrm{C}_{16: 1} \omega 7 \mathrm{c}\right.$ and/or $\left.\mathrm{C}_{16: 1} \omega 6 c\right)$. Phosphatidylglycerol, diphosphatidylglycerol, and phosphatidylethanolamine are the major polar lipids and a minor polar lipid, an unidentified aminophospholipid, is also present.

The type strain is $\mathrm{B} 156^{\mathrm{T}}\left(=\mathrm{KACC} 21665^{\mathrm{T}}=\mathrm{JCM} 33920^{\mathrm{T}}\right)$, isolated from mountain soil of Gangwon province in South Korea. The DNA G+C content calculated from the whole genome sequence of the type strain is $69.3 \mathrm{~mol} \%$. The GenBank accession numbers of the $16 \mathrm{~S}$ rRNA gene and genome sequences of strain B156 ${ }^{\mathrm{T}}$ are MN620391 and JABFCS000000000, respectively.

\section{Acknowledgments}

We thank Prof. Aharon Oren for his expert suggestion for correct species epithet and Latin etymology. This work was supported by the Program for Collection of Domestic Biological Resources from the National Institute of Biological Resources (NIBR No. 2020-02-001) of the Ministry of Environment (MOE) and the National Research Foundation (2017M3C1B5019250) of the Ministry of Science and ICT, Republic of Korea.

\section{Conflicts of Interest}

The authors have no financial conflicts of interest to declare.

\section{References}

1. Heulin T, Barakat M, Christen R, Lesourd M, Sutra L, De Luca G, et al. 2003. Ramlibacter tataouinensis gen. nov., sp. nov., and Ramlibacter henchirensis sp. nov., cyst-producing bacteria isolated from subdesert soil in Tunisia. Int. J. Syst. Evol. Microbiol. 53: 589594.

2. Lee DH, Cha CJ. 2017. Ramlibacter alkalitolerans sp. nov., alkali-tolerant bacterium isolated from soil of ginseng. Int. J. Syst. Evol. Microbiol. 67: 4619-4623.

3. Wang L, An DS, Kim SG, Jin FX, Kim SC, Lee ST, et al. 2012. Ramlibacter ginsenosidimutans sp. nov., with ginsenoside-converting activity. J. Microbiol. Biotechnol. 22: 311-315.

4. Lee HJ, Lee SH, Lee SS, Lee JS, Kim Y, Kim SC, et al. 2014. Ramlibacter solisilvae sp. nov., isolated from forest soil, and emended description of the genus Ramlibacter. Int. J. Syst. Evol. Microbiol. 64: 1317-1322.

5. Chaudhary DK, Kim J. 2017. Ramlibacter monticola sp. nov., isolated from forest soil. Int. J. Syst. Evol. Microbiol. 67: $4468-4474$.

6. Zhang XJ, Feng GD, Yao Q, Wang YH, Yang SZ, Zhu HH. 2019. Ramlibacter humi sp. nov., isolated from tropical forest soil. Int. J. Syst. Evol. Microbiol. 69: 3460-3464.

7. Yan ZF, Trinh H, Moya G, Lin P, Li CT, Kook M, et al. 2017. Ramlibacter rhizophilus sp. nov., isolated from rhizosphere soil of national flower Mugunghwa from South Korea. Int. J. Syst. Evol. Microbiol. 67: 3773-3777.

8. Akter S, Nam K, Lee SY, Moon SK, Choi C, Balusamy SR, et al. 2020. Ramlibacter pinisoli sp. nov., a novel bacterial species isolated from pine garden soil. Int. J. Syst. Evol. Microbiol. 70: 5841-5847.

9. Props R, Monsieurs P, Vandamme P, Leys N, Denef VJ, Boon N. 2019. Gene expansion and positive selection as bacterial adaptations to oligotrophic conditions. mSphere 4: e00011-19.

10. Khan SA, Jung HS, Park HY, Jeon CO. 2021. Maritimibacter harenae sp. nov. and Sneathiella litorea sp. nov.: members of Alphaproteobacteria isolated from sea sand. Antonie Van Leeuwenhoek. 114: 799-811.

11. Yoon SH, Ha SM, Kwon S, Lim J, Kim Y, Seo H, et al. 2017. Introducing EzBioCloud: A taxonomically united database of $16 \mathrm{~S}$ rRNA and whole genome assemblies. Int. J. Syst. Evol. Microbiol. 67: 1613-1617.

12. Wang Q, Garrity GM, Tiedje JM, Cole JR. 2007. Naïve Bayesian classifier for rapid assignment of rRNA sequences into the new bacterial taxonomy. Appl. Environ. Microbiol. 73: 5261-5267.

13. Kumar S, Stecher G, Tamura K, Dudley J. 2016. MEGA7: molecular evolutionary genetics analysis version 7.0 for bigger datasets. Mol. Biol. Evol. 33: 1870-1874.

14. Sambrook J, Fritsch EF, Maniatis T. 1989. Molecular cloning: a laboratory manual, 2nd, Ed. Cold Spring Harbor, NY: Cold Spring Harbor Laboratory.

15. Wick RR, Judd LM, Gorrie CL, Holt KE. 2017. Unicycler: Resolving bacterial genome assemblies from short and long sequencing reads. PLoS Comput. Biol. 13: e1005595.

16. Parks DH, Imelfort M, Skennerton CT, Hugenholtz P, Tyson GW. 2019. CheckM: assessing the quality of microbial genomes recovered from isolates, single cells, and metagenomes. Genome Res. 25: 1043-1055.

17. Lee I, Ouk Kim Y, Park SC, Chun J. 2016. OrthoANI: an improved algorithm and software for calculating average nucleotide identity. Int. J. Syst. Evol. Microbiol. 66: 1100-1103.

18. Meier-Kolthoff JP, Auch AF, Klenk H-P, Göker M. 2013. Genome sequence-based species delimitation with confidence intervals and improved distance functions. BMC Bioinformatics 14: 60 .

19. Kim J, Na SI, Kim D, Chun J. 2021. UBCG2: up-to-date bacterial core gene and pipeline for phylogenomic analysis. J. Microbiol. 59: 609-615.

20. Gomori G. 1955. Preparation of buffers for use in enzyme studies. Methods Enzymol. 1: 138-146.

21. Bernardet JF, Nakagawa Y, Holmes B. 2002. Proposed minimal standards for describing new taxa of the family Flavobacteriaceae and emended description of the family. Int. J. Syst. Evol. Microbiol. 52: 1049-1070. 
22. Tindall BJ, Sikorski J, Smibert RA, Krieg NR. 2007. Phenotypic characterization and the principles of comparative systematics. In Methods for General and Molecular Microbiology, pp. 330-393. Edited by Reddy CA, Beveridge TJ, Breznak JA, Marzluf G, Schmidt TM, Snyder LR. Washington DC: American Society for Microbiology.

23. Lányi B. 1987. Classical and rapid identification methods for medically important bacteria. Methods Microbiol. 19: 1-67.

24. Minnikin DE, O’Donnell A, Goodfellow M, Alderson G, Athalye M, Schaal A, et al. 1984. An integrated procedure for the extraction of bacterial isoprenoid quinones and polar lipids. J. Microbiol. Methods 2: 233-241.

25. Sasser M. 1990. Identification of bacteria by gas chromatography of cellular fatty acids, MIDI Technical Note 101.MIDI Inc, Newark.

26. Minnikin DE, Patel PV, Alshamaony L, Goodfellow M. 1977. Polar lipid composition in the classification of Nocardia and related bacteria. Int. J. Syst. Evol. Microbiol. 27: 104-117.

27. Chun J, Oren A, Ventosa A, Christensen H, Arahal DR, da Costa MS, et al. 2018. Proposed minimal standards for the use of genome data for the taxonomy of prokaryotes. Int. J. Syst. Evol. Microbiol. 68: 461-466. 